\title{
Performance of Photovoltaic Modules After an Accelerated Thermal Cycling Degradation Test
}

\author{
Aramis Perez ${ }^{1,2}$, Luis G. Marín ${ }^{3}$, Fernando Fuentes ${ }^{4}$, Patricio Mendoza ${ }^{5}$, Guillermo Jimenez ${ }^{6}$, and Marcos Orchard ${ }^{7}$ \\ 1,5,7 Department of Electrical Engineering, University of Chile, Av. Tupper 2007, Santiago, Chile \\ aramis.perez@ing.uchile.cl \\ pmendoza@ing.uchile.cl \\ morchard@ing.uchile.cl \\ ${ }^{2}$ School of Electrical Engineering, University of Costa Rica, San Jose, Costa Rica \\ aramis.perez@ucr.ac.cr \\ ${ }^{3}$ Cycle System, Cra. 25 \#41-94, Bogotá, Colombia \\ luis.marin@cyclesystem.org \\ ${ }^{4}$ Energy Center, University of Chile, Av. Tupper 2007, Santiago, Chile \\ ffuentes@centroenergia.cl \\ ${ }^{6}$ Department of Electrical and Electronics Engineering, Universidad de Los Andes, Bogotá, 111711, Colombia \\ ga.jimeneze@uniandes.edu.co
}

\begin{abstract}
Typically, datasheets of photovoltaic (PV) modules state that the guaranteed power production remains constant for a certain period of time and after this point, a linear reduction begins reaching an estimated $80 \%$ of the original rated power. Moreover, literature reports that the degradation of PV modules reaches less than $1 \%$ per year. In this regard, after 20 years of operation a typical PV module will deliver approximately $20 \%$ less energy than at the beginning of its life. In this article, the results of an accelerated thermal cycling degradation test are compared to its brand new conditions. These results demonstrate that although the performance among the PV modules is variable when new, after the cycling test the performance of the degraded PV modules is similar. In this case, the power reduction of the degraded module varies from $1.4 \%$ up o $7.6 \%$ when compared to the initial condition. Furthermore, an Electrochemical Impedance Spectroscopy (EIS) analysis demonstrates that at high frequencies the results are practically the same regardless if the panel is new or degraded, but at low frequencies the variation of the impedance is notorious.
\end{abstract}

Aramis Perez et al. This is an open-access article distributed under the terms of the Creative Commons Attribution 3.0 United States License, which permits unrestricted use, distribution, and reproduction in any medium, provided the original author and source are credited.

\section{INTRODUCTION}

It is no secret that climate change is occurring. For this reason, different efforts around the world to substitute fossil fuels with cleaner energy sources is an ongoing trend. One of the most popular alternatives comes from the use of PV sources, specifically PV modules, due to the increase on their efficiency, enhanced durability, and notorious diminishment of the fabrication costs of PV modules. Currently, the guaranteed lifespan of PV modules can be of a couple of decades. Hence, it becomes of great importance to understand its degradation process through the assistance of laboratory test procedures that accelerate the degradation process. This way manufacturers can start commercializing their products without having to wait for the results of the natural degradation process. Furthermore, standardized laboratory tests are required for quality and safety assurance of the products hence generating confidence to the buyers and users.

The power output of PV modules depends on the amount of solar radiation and temperature, which in turn change with time and season. For that reason, the diagnosis of PV modules is an important topic in order assess the degradation of PV modules. The most common types of failures and degradation causes of PV cells are mechanical stress, interconnect ribbon disconnection, and potential-induced degradation. In 
turn, mechanical stress can be originated from installation strain, exogenous shock, and thermal stress from the temperature cycling of day and night, or variations of solar radiation (Katayama, Osawa, Matsumoto, Nakano, \& Sugiyama, 2019; Huang \& Wang, 2018; Ndiaye, Charki, et al., 2013). Due to environmental conditions and different internal stresses, PV modules can degrade before meeting the manufacturers warranty of 25 years lifetime (Omazic et al., 2019).

Several methods such as I-V characteristic curve, thermography, visual inspection, ultraviolet fluorescence, impedance spectroscopy, etc. are reported in the literature to characterize different faults and degradation in PV modules (Olayiwola \& Barendse, 2018), since these techniques yield good results. Current-voltage (I-V) curves are widely used to obtain information on the performance of PV modules. Distortions of the I-V curves appear when a malfunction of the module occurs.

This article illustrates the performance of several PV modules before and after being submitted to an accelerated thermal cycling degradation test. The PV modules are submitted to qualification tests with standards from the International Electrotechnical Commission (IEC). The influence of radiation and temperature on the performance characteristics is studied, on new and degraded modules. The performance of the PV modules is analyzed through I-V curves, under different environmental and seasonal conditions. Also an EIS test is done to measure the internal impedance of the modules with the intention to capture the internal dynamics than can not be quantified with the traditional I-V or power curves. The results of the EIS test are illustrated with a Nyquist plot.

The main contribution of this work is to illustrate the different performance results under different operating conditions, and how the traditional $\mathrm{I}-\mathrm{V}$ analysis is not enough to differentiate between new and degraded modules, and how additional tests are required to determine the real state of health condition of a PV module. In this regard, the analysis of the internal impedance is helpful, but the evidence shows that only a certain range of frequencies is possible to assess the real state of health condition of a PV module.

This paper is organized as follows: Section 2 presents theoretical framework of the modeling PV modules. Section 3 describes the proposed methodology and results. The last section provides the main conclusions of this work.

\section{TheOretical FrameWORK}

\subsection{Modeling PV Modules}

A PV module is composed of a number of series and parallel connected PV cells. The combination of a various PV modules interconnected in series and parallel can be called a string or an array depending on the configuration. A solar cell is usually represented by an electrical equivalent one- diode model (Cibira, 2018; Huang \& Wang, 2018), as shown in Figure 1.

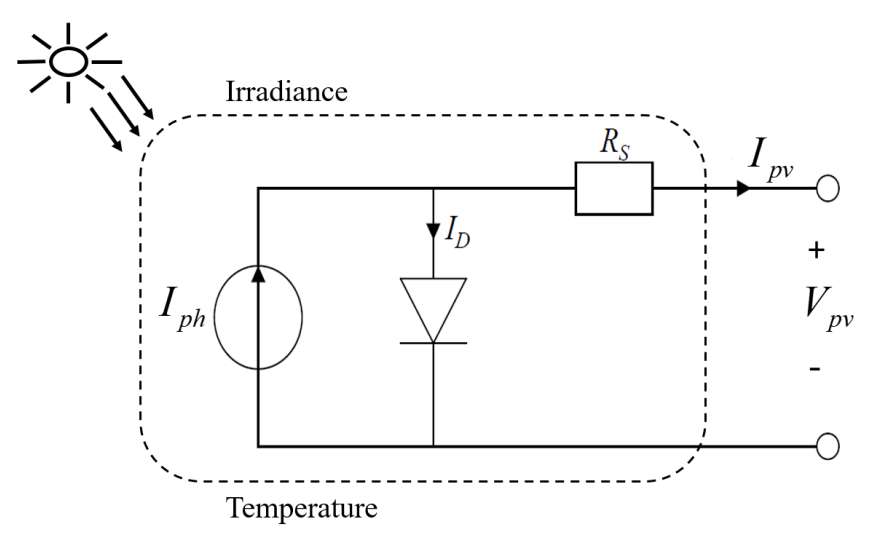

Figure 1. Electrical equivalent circuit of PV cell

This model contains a current source $I_{p h}$ which is connected in parallel with a diode, and a series resistance $R_{s}$, which represents the resistance inside each cell and in the connection between the cells (Mittal, Bora, Saxena, \& Gaur, 2018). The net current produced by the cell $I_{p v}$ is obtained directly from Kirchhoff's law:

$$
\begin{gathered}
I_{p v}=I_{p h}-I_{D} \\
I_{p v}=I_{p h}-I_{0}\left(\exp ^{\left(e\left(V_{p v}+I_{p v} R_{s}\right) /\left(m k T_{c}\right)\right)}-1\right)
\end{gathered}
$$

where $e$ is the electronic charge, $m$ is the ideality factor of the diode, $k$ is Boltzmann's gas constant, $T_{c}$ is the absolute temperature of the cell, $V_{p v}$ is the voltage of the cell and $I_{0}$ is the reverse saturation current of the diode which is strongly dependant on the temperature. Finally, $I_{p h}$ is the photo-current given by:

$$
I_{p h}=\left(I_{p h, n}+k_{1} \Delta T\right) \frac{G_{a}}{G_{n}}
$$

where $I_{p h, n}$ is the nominal photo-current, $k_{1}$ corresponds to the temperature coefficient of the short-circuit current, $\Delta T=$ $T_{m}-T_{n}$ with $T_{m}$ being the module temperature and $T_{n}=$ $25^{\circ} \mathrm{C}$ as the nominal temperature, $G_{a}$ is the irradiance, and $G_{n}=1000 \mathrm{~W} / \mathrm{m}^{2}$ is the nominal irradiance (Azizi et al., 2018).

Typically, a PV module can be characterized by the following electrical characteristics: short-circuit current $\left(I_{s c}\right)$, opencircuit voltage $\left(V_{o c}\right)$, maximum power output $\left(P_{\max }\right)$, maximum efficiency $(\eta)$, and fill factor (Ndiaye, Kb, et al., 2013). It is important to note that the I-V characteristics of every PV cell change with ambient conditions. In particular, the short circuit current increases linearly with the irradiation while open circuit voltage increases logarithmically with the ambient irradiation. Additionally, the open circuit voltage decreases linearly with the temperature while short circuit cur- 
rent slightly increases with cell temperature. Therefore, in order to ensure that the generated power from the PV cell is maximized, the operating voltage needs to be adjusted dynamically with respect to the changing temperature of the PV module and irradiation (maximum power point tracking). The fill factor diminishes as the cell temperature is increased and a value higher than 0.7 represents good cells. Finally, the maximum efficiency $\eta$ is given by:

$$
\eta=\frac{P_{\max }}{A G_{a}}
$$

where $A$ is the cell area and $G_{a}$ is the ambient irradiation. As PV modules are composed of cells, the module current $I^{M}$ under the specific value of module voltage $\left(V_{M}\right)$, ambient temperature $\left(T_{a}\right)$, and outdoor irradiance $\left(G_{a}\right)$ is described as:

$$
I^{M}=I_{s c}^{M}\left[\frac{1-\exp \left(V_{M}-V_{o c}^{M}+I^{M} R_{s}^{M}\right)}{N_{S M} V_{t}^{C}}\right]
$$

where $I_{s c}^{M}, V_{o c}^{M}$ and $R_{s}^{M}$ represent the modules short circuit current, open circuit voltage and series resistance. $N_{S M}$ is the number of series connected cells, and $V_{t}^{C}$ is the thermal voltage for a single cell.

\subsection{Degradation in PV Modules}

Degradation is a gradual process in which the quality and ability of a component or a system to operate within the limits of acceptability are affected. Therefore, the degradation of PV modules is assessed comparing the current power and the delivered power when the module is new. According to manufacturers, a PV module is degraded when its power reaches a level below $80 \%$ of its initial power. When this occurs, the PV modules operate outside the expected quality limits, therefore negatively impacting on the performance, and subsequently increasing costs, as well as reducing the working life of the panel (Silva, Melo, Reis, \& Freitas, 2019). Temperature, humidity and UV radiation are the main environmental parameters that could degrade the PV modules.

The lifespan of a PV module depends mainly on the energy performance of modules and their different modes of degradation (Laronde, Charki, \& Bigaud, 2013). The existing literature focus more on laboratory tests rather than experimental tests. However, most of these results obtained from laboratory tests are not always accurate and consistent with the expected degradation rates of PV modules. In 2002, the National Renewable Energy Laboratory (NREL) estimated the annual performance degradation of monocrystalline and polycrystalline PV modules at $0.7 \%$ (Osterwald, Anderberg, Rummel, \& Ottoson, 2002). The Laboratory of Energy, Ecology and Economy Solar-Ticino in Switzerland (LEEE-TISO), stated that the power degradation rate of crystalline silicon PV modules could go from $0.7 \%$ to $9.8 \%$ during the first year of exposure, and $0.7 \%$ to $4.9 \%$ during the second year.

For the above reason in this study, the EIS is used to determine accurate and consistent degradation rates. This method is widely used to evaluate electrochemical devices, as well as a diagnostic tool for PV modules (Osawa et al., 2016). This method adds a small AC voltage at a certain frequency ranges onto the DC voltage of the PV module which produces an $\mathrm{AC}$ current response at the same frequency. Therefore, the impedance at that frequency is obtained from the $\mathrm{AC}$ voltage and current and finally, scanning the frequency range and plotting the impedance for each frequency on a complex plane gives a Nyquist plot in order to analyze the degradation rate (Katayama et al., 2019). The EIS measurement is an important tool to reveal the degradation changes due to high voltage stress and environmental stress such as temperature. In this method, the impedance characteristics with and without failure and degradation of modules are measured as Nyquist plots to be used as a diagnostic tool for PV modules (Váry, Sály, Packa, Perný, \& Schlosser, 2015). The Nyquist plot shows on the complex plane the real part of a Frequency Response Functions (FRF) against its imaginary part with frequency as an implicit variable. The benefit of using Nyquist plot comes from the circularity of an FRF on the complex plane, additionally, it is very sensitive to changes and some parameters can be read from the plot (Al-Khazali \& Askari, 2012). The Nyquist plot of the impedance spectrum is mostly used to extract the relevant parameters of the device under test, in this case, PV modules. These parameters can be compared and monitored under different condition because the Nyquist curve reflects the systems response to different frequencies.

\subsection{PV Module Standards}

The International Electrotechnical Commission (IEC) is a non-profit organization founded at he beginning of the Twentieth Century, and one of its duties consists on publishing international standards for electric and electronic products. One of its technical committees (TC 82) is in charge of the solar photovoltaic energy systems, and one of its standards, the IEC 61215 , focuses on terrestrial PV modules, and it consists of two parts:

- Part 1: Special requirements for testing different technology-based PV modules.

- Part 2: Test procedures.

The main intention of this standard is to define the necessary test requirements for PV modules to operate in open-air climates during a long period of time and complying with the specified quality conditions. In other words, the idea is to define the thermal and electrical characteristics that the PV module has to meet within the defined constraints of cost and time in order to function properly for an extended period of 
time. Since, it is unrealistic for a company to wait a couple of decades to determine if their product indeed has a lifetime of decades, using accelerated testing becomes helpful to emulate the degradation process. For this reason, the IEC 61215 regulates a series of accelerated tests to evaluate the performance of PV modules. For instance, some of procedures include the characterization and tests for degradation assessment. Within the degradation procedures, several factors as environmental, electrical and mechanical are considered. One of the degradation tests consists of an accelerated thermal cycling test. Some of the faults that can be detected with this test are:

- Broken interconnections or cells

- Electrical bond failures

- Junction box adhesion

- Module open circuit

The idea behind the thermal cycle is to submit the PV modules to extreme temperatures continuously. The procedure is described as follows:

1. Begin the experiment at $25^{\circ} \mathrm{C}$.

2. During the next hour begin reducing the temperature in a linear manner until it reaches $-40{ }^{\circ} \mathrm{C}$ after the 60 minutes.

3. Once the $-40{ }^{\circ} \mathrm{C}$ are reached, maintain the temperature constant for 10 minutes.

4. After the 10 minutes, begin rising the temperature linearly during 120 minutes until it reaches $85^{\circ} \mathrm{C}$.

5. Hold the temperature at $85^{\circ} \mathrm{C}$ for 10 minutes.

6. After the 10 minutes, reduce the temperature linearly during 120 minutes until it reaches $-40{ }^{\circ} \mathrm{C}$.

7. A cycle is complete. Repeat starting from Step 3, and count 200 cycles.

\section{Methodology}

\subsection{Case Study}

For this article, four 20 Watt PV modules were considered. The modules were purchased in Chile and manufactured under the brand Sako. This PV modules can be considered of the low cost type. Even though no data sheet was provided by the manufacturer some characteristics were attached on the backside of the module. The fabrication characteristics and electrical characteristics under standard testing conditions (STC) labeled are:

- Cell Type: Mono Cell

- Glass Type: Toughened Glass

- Laminate: EVA

- ISO 9000:2000

- IEC 61215 Standard

- Maximum Power Tolerance: $\pm 3 \%$

- Open Circuit Voltage: $21.24 \mathrm{~V}$
- Short Circuit Current: $1.2 \mathrm{~A}$

- Maximum Power Voltage: $18.0 \mathrm{~V}$

- Maximum Power Current: $1.1 \mathrm{~A}$

The first step of the procedure was to measure the internal impedance of the modules through an EIS test. This way an initial value could be established prior to the accelerated degradation test. The second step of the study was to characterize the electrical performance of the brand new modules. For this characterization, the measurements were done on a rooftop in the city of Santiago during the summer (high radiation conditions). After these two steps, two of the modules were submitted to the accelerated degradation thermal cycle, while the others were stored for control purposes after the test. It is important to mention that one small variation had to be done on the thermal cycling test, due to a constraint on the temperature chamber. The lowest temperature that the chamber could reach is $-34{ }^{\circ} \mathrm{C}$, therefore this value was set to be the limit of the thermal cycling. After the 200 thermal cycles, the modules were submitted to the internal impedance EIS test, and to the electrical characterization measurements to compare the results. To assess the performance of the PV modules under different environmental conditions, a second measurement was made two months apart from the initial measurements. Since the first results were at high radiation and high temperature conditions (summer), this second set of measurements were done at moderate radiation and temperature values (autumn conditions). During the period between measurements, the PV modules were stored and not used. The next section illustrates the obtained results.

\subsection{Results}

As mentioned previously, the four PV modules were classified as either control modules or degraded modules. The first step consisted on measuring the internal impedance of the modules. Figure 2 shows the obtained Nyquist plot for the four modules prior to the accelerated test. It can be noted that all the modules have a similar behavior at high frequencies, however there is a point where each curve follows a different path.

To understand the electrical perfomance of the PV modules, the I-V curve is required. Figure 3 shows the I-V curve for the PV modules when new. Despite that most of the modules had similar internal impedance values, the electrical characteristics show that there is no clear differences among the modules. Table 1 shows the values obtained from electrical characterization. The variables described in Table 1 correspond to: open circuit voltage, short-circuit current, in-plane irradiance, ambient temperature, module temperature, finally voltage and current at the maximum power point.

As seen on Table 1, there are small variations on the results when compared among each other, and when related to the 
Table 1. Electrical characteristics of the brand new PV modules.

\begin{tabular}{l|l|l|l|l|l|l|l}
\hline \hline Module Number & Voc [V] & Isc [A] & Irr [W/m2] & Ta $^{\circ} \mathbf{C}$ & Tpv $^{\circ} \mathbf{C}$ & Vmpp [V] & Impp [A] \\
\hline \hline 1 & 17.1 & 1.17 & 1002 & 34 & 54 & 15.05 & 1.1 \\
\hline 2 & 17.5 & 1.41 & 1016 & 35 & 60 & 14.81 & 1.3 \\
\hline 3 & 17.5 & 1.41 & 1023 & 35 & 60 & 14.91 & 1.3 \\
\hline 4 & 18.7 & 1.25 & 945 & 36.5 & 49.2 & 16.47 & 1.1 \\
\hline
\end{tabular}

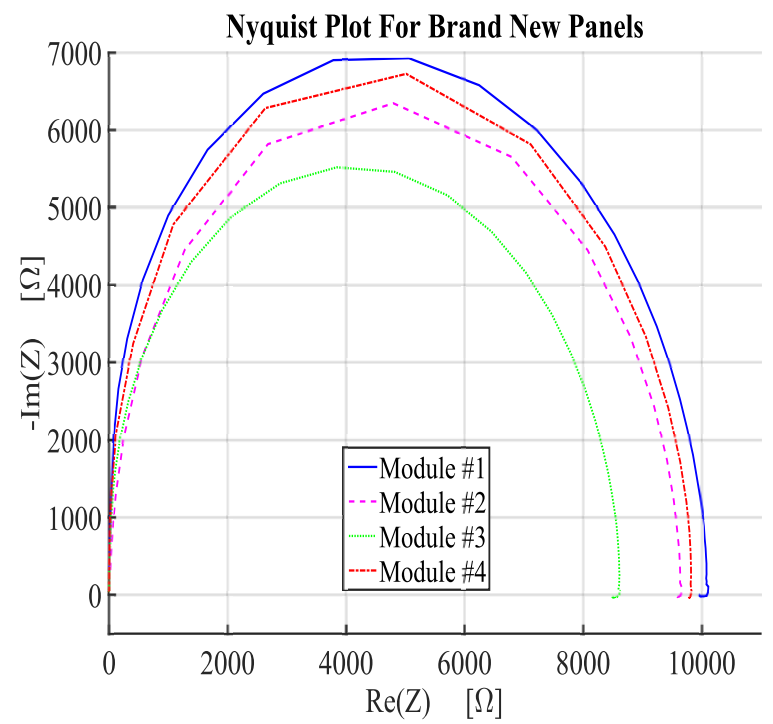

Figure 2. Nyquist plot for the brand new PV modules.

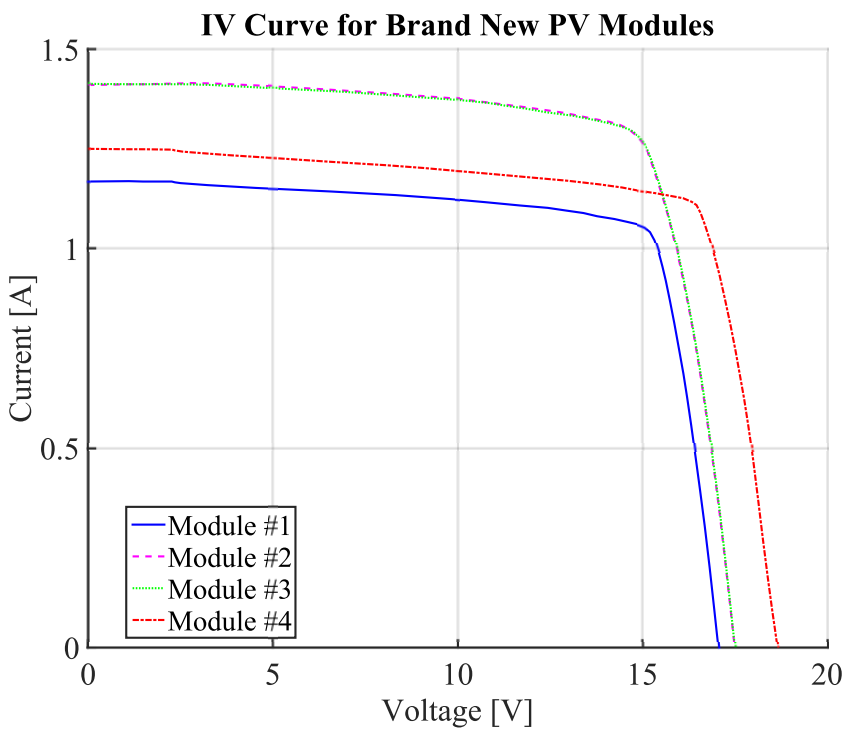

Figure 3. I-V Curve for the brand new PV modules.

specified characteristics from the manufacturer. These variations can be associated both to small constructive differences, the chemistry, or to the irradiance at the time of the measurement. However, the measurements were done within less than 5 minutes apart in total. After these measurements, Modules
\#3 and \#4 were submitted to the thermal cycling procedure. Figure 4 shows the comparison between the initial and the degraded conditions. The I-V curves show how the degraded modules have a similar performance between them, regardless that when new the differences can be easily noted. However, if each of these two modules is compared with itself there are significant changes on their performance. Table 2 shows the I-V curve characterization results of Modules \#3 and \#4 after the thermal cycling process. It can be noted that even the small differences in the radiation value, the degraded modules has lower short-circuit and MPP current values than when they were brand new. In this case, it is important to point that the measurements have different PV module temperatures, and despite this fact, the MPP power delivered by the degraded modules is always less than when new. In case of Module \#3, is nearly $7.6 \%$, and Module \#4 is close to $1.4 \%$. The issue with the temperature is that having similar ambient and module temperatures between $30^{\circ} \mathrm{C}$ to $35^{\circ} \mathrm{C}$ should benefit the energy production, but in this case since the modules are degraded the power produced is less.

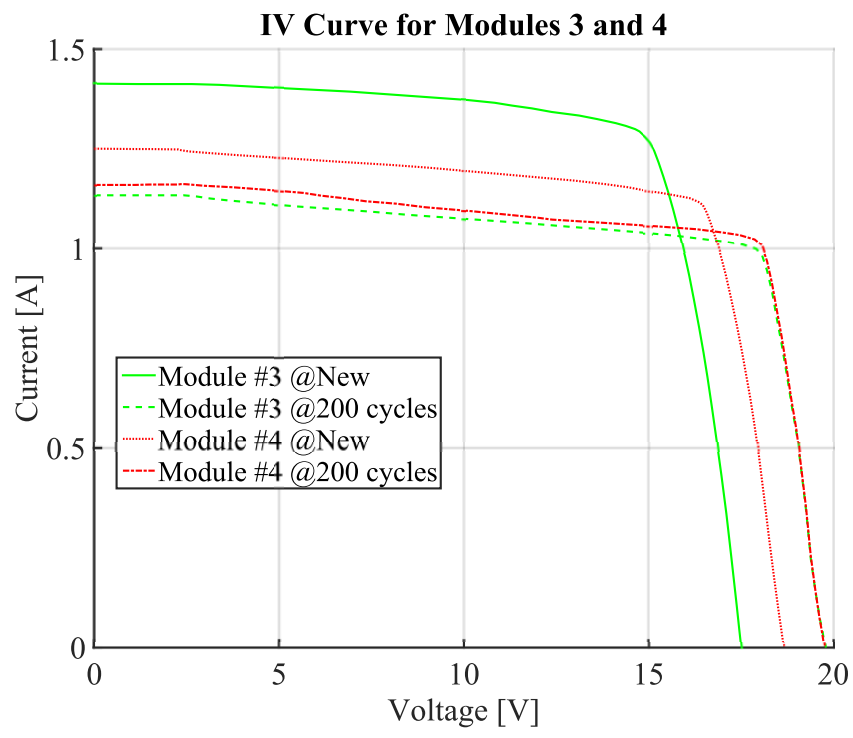

Figure 4. Comparison through the I-V Curve of the PV modules when new and after the thermal cycling.

The next step consisted on measuring the changes of the internal impedance of the degraded modules through an EIS test. Figure 5 shows the Nyquist plot for Modules \#3 and \#4. The frequency range of this curve is from $5 \mathrm{mHz}$ up to $10 \mathrm{kHz}$. 
Table 2. Electrical characteristics of the degraded PV modules.

\begin{tabular}{l|l|l|l|l|l|l|l}
\hline \hline Module Number & Voc [V] & Isc [A] & Irr [W/m2] & Ta $^{\circ} \mathbf{C}$ & $\mathbf{T p v}^{\circ} \mathbf{C}$ & Vmpp [V] $_{1}$ & Impp [A] \\
\hline \hline 3 & 19.8 & 1.33 & 1004 & 33.3 & 33.1 & 17.9 & 1 \\
\hline 4 & 19.8 & 1.16 & 998 & 33.16 & 33.4 & 17.87 & 1 \\
\hline
\end{tabular}

In this plot, an interesting fact can be observed. The high frequencies of this plot are located at the $(0,0)$ coordinate and at these frequencies the Nyquist plot is very similar to both modules, regardless if they are new or degraded. At middle range frequencies the behavior of the curves is uneven since for example the degraded plot for Module \#3 goes above the original plot, while with Module \#4 occurs the opposite (although it comes a point where the degraded curve crosses the original). However, the most important characteristic occurs at low frequencies, at the intersection with the imaginary axis, where there impedance is just a resistance. In both cases, it is notorious how the resistance of the modules increased after the thermal cycling process. Table 3 shows the obtained resistance values of the modules. The variation of the resistance or this modules ranges between $7 \%$ and $17 \%$.

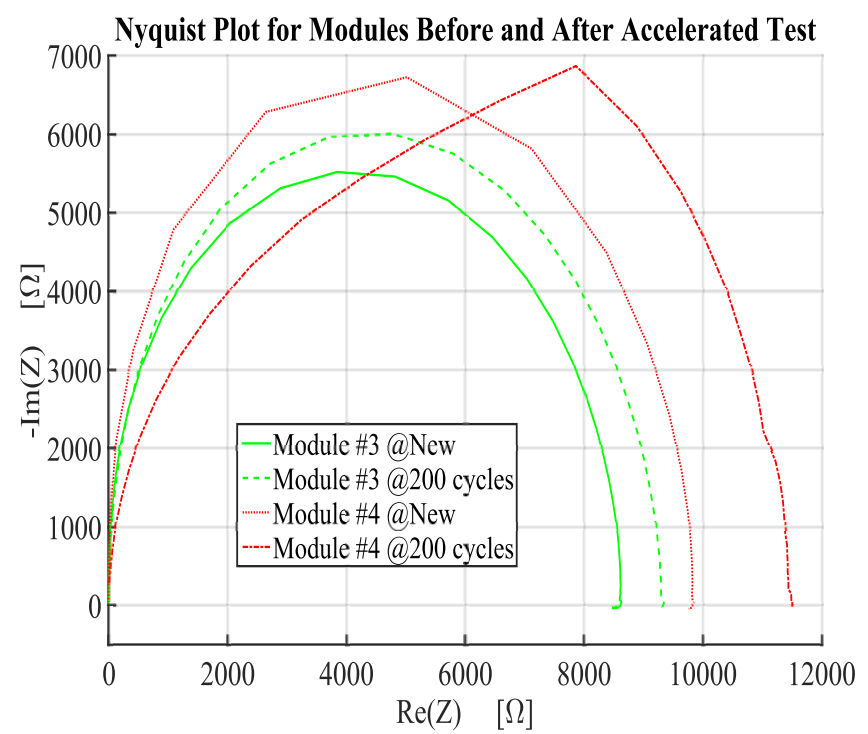

Figure 5. Nyquist plot of the PV modules when new and after the thermal cycling.

After two months of storage (the purpose of this storage was to wait for the new season, autumn, in order to perform the measurements to generate the I-V curves). Figure 6 illustrates the obtained I-V curve results plus the performance of the modules when new (same as Figure 3). This measurement was done in two different conditions of the same day (morning and afternoon). The main purpose of doing this is to have similar temperature conditions (ambient and module surface) in the morning, and by leaving the modules for a couple of hours create a different temperature condition. Table 4 shows the obtained results of the I-V characterization curve.
From Figure 6 it can be noted that for the morning conditions there are no clear differences between the new and the degraded modules, since the degraded I-V curves have operating conditions between the two brand new modules. However, due to the weather conditions and clouds of the day, it can be appreciated that for Module \#2 during the morning conditions, the I-V curve dropped nearly at $3 \mathrm{~V}$.

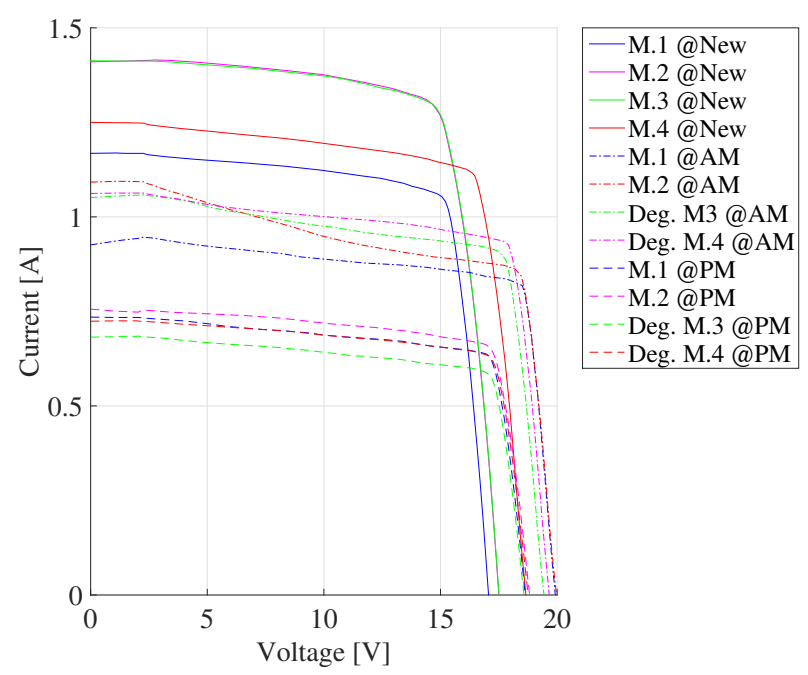

Figure 6. Comparison through the I-V Curve of the PV modules at different moments.

A different scenario occurs in the afternoon conditions, since there is less radiation, but now there is an approximately 10 ${ }^{\circ} \mathrm{C}$ delta, between the ambient and the PV module surface temperature. In this case, it becomes more notorious how the capacity of producing energy is less in all modules (new and degraded). An interesting fact, is that Module \#3 had at the beginning of the experiment the best performance (as well as Module \#2), but at the autumn conditions had the worst performance, while Module \#2 was still the module with best performance. Furthermore, from Table 4 it can be observed that during the morning and afternoon conditions the performance of the new modules and the degraded modules is very similar.

When the all the modules were new and the measurements were made in high radiation and temperature conditions (summer), due to the manufacturing differences there were noticeable performance variances among the four modules. It is clear that the environmental conditions affect the performance of the PV modules, specially the variance of the radia- 
Table 3. Internal resistance of the new and degraded modules at low frequencies.

\begin{tabular}{l|l|l|l}
\hline \hline Module Number & Initial Resistance [k $\Omega]$ & Final Resistance [k $\Omega]$ & Resistance Increase [\%] \\
\hline \hline 3 & 8.6 & 9.22 & 7.2 \\
\hline 4 & 9.81 & 11.49 & 17.12 \\
\hline
\end{tabular}

Table 4. Electrical characteristics of PV modules at different conditions.

\begin{tabular}{l|l|l|l|l|l|l|l}
\hline \hline Module Number & Voc $[\mathbf{V}]$ & Isc $[\mathbf{A}]$ & Irr [W/m2] & Ta $^{\circ} \mathbf{C}$ & $\mathbf{T p v}^{\circ} \mathbf{C}$ & $\mathbf{V m p p}[\mathbf{V}]$ & $\mathbf{I m p p}[\mathbf{A}]$ \\
\hline \hline 1 (AM Conditions) & 19.9 & 0.927 & 895.3 & 25.42 & 28.39 & 18.51 & 0.8 \\
\hline 2 (AM Conditions) & 20.0 & 1.092 & 896 & 25.35 & 28.4 & 18.2 & 0.9 \\
\hline 3 (AM Conditions) & 19.4 & 1.052 & 892.1 & 25.66 & 27.78 & 17.48 & 0.9 \\
\hline 4 (AM Conditions) & 19.7 & 1.062 & 897 & 25.85 & 28.39 & 17.92 & 0.9 \\
\hline 1 (PM Conditions) & 18.6 & 0.735 & 635 & 24.04 & 35.14 & 16.98 & 0.6 \\
\hline 2 (PM Conditions) & 18.8 & 0.757 & 631 & 25.71 & 35.51 & 16.94 & 0.7 \\
\hline 3 (PM Conditions) & 18.6 & 0.683 & 635.5 & 26.65 & 35.85 & 16.91 & 0.6 \\
\hline 4 (PM Conditions) & 18.8 & 0.724 & 636.4 & 26.51 & 34.94 & 17.1 & 0.6 \\
\hline
\end{tabular}

tion. For example, in high radiation conditions, the change of the power characteristics are notorious when the new module is compared to its degraded state (Modules \#3 and \#4). However, when the radiation conditions change (in this case, due to seasonality), it becomes difficult to differentiate the performance of new and degraded modules. For instance, in autumn conditions the performance of the new and the degrade modules can not be easily noted just with the I-V curve or the electrical characteristics, although that in the afternoon measurements the performance of the degraded modules were the worst, but not for a quantitative difference. Moreover, just by looking the curves of Figure 6 or the results of Table 4 it is complex to determine which modules are new and which ones are degraded. For this reason, it becomes of utmost importance to develop a low frequency-based test to analyze the changes on the internal resistance of the PV modules. In this way, a parameter that is not dependant of the environmental conditions can set the ground-truth for determining the real state of health condition of a PV module.

\section{Conclusions}

The use of an I-V curve to characterize the performance of a PV module it is helpful but sometimes might not be enough. It is important to always keep in mind that small changes in the radiation affect the amount of power that can be delivered. Having a large database with combined environmental conditions is desired for comparison purposes, however it is very difficult for a user to have access to this kind of information. The performed tests showed that the initial conditions of the four modules are very different, but after the accelerated thermal degradation test the performance is very similar between the two degraded modules. However, in low radiation conditions it is difficult to note the differences among the modules. To determine the internal resistance value of a PV module, a low frequency excitation test can be used to analyze the evo- lution of this parameter in time or when compared to its value when new. The test can not be done at high frequencies since there are no observable differences, and in the middle range frequencies the interpretation can be ambiguous.

\section{ACKNOWLEDGMENTS}

This work has been partially supported by FONDECYT Chile Grant Nr. 1170044, the Advanced Center for Electrical and Electronic Engineering, AC3E, Basal Project FB0008, CONICYT, and ATAMOSTEC (Atacama Module and System Technology Consortium) Project. The work of Aramis Perez was supported by the University of Costa Rica (Grant for Doctoral Studies) and CONICYT-PCHA/Doctorado Nacional/2015-21150121. Luis G. Marin was supported by a scholarship from COLCIENCIAS-Colombia and CONICYTPCHA/Doctorado Nacional para extranjeros/2014-63140093.

\section{REFERENCES}

Al-Khazali, H. A., \& Askari, M. R. (2012). Calculations of frequency response functions (frf) using computer smart office software and nyquist plot under gyroscopic effect rotation. arXiv preprint arXiv:1208.3681.

Azizi, A., Logerais, P.-O., Omeiri, A., Amiar, A., Charki, A., Riou, O., ... Durastanti, J.-F. (2018). Impact of the aging of a photovoltaic module on the performance of a grid-connected system. Solar Energy, 174, 445 - 454. doi: https://doi.org/10.1016/j.solener.2018.09.022

Cibira, G. (2018). Pv cell electrical parameters dynamic modelling based on double-diode five-parameter reduced forms. Applied Surface Science, 461, 98 - 101. doi: https://doi.org/10.1016/j.apsusc.2018.05.195

Huang, C., \& Wang, L. (2018). Simulation study on the degradation process of photovoltaic modules. Energy Conversion and Management, 165, 236 - 243. doi: 
https://doi.org/10.1016/j.enconman.2018.03.056

Katayama, N., Osawa, S., Matsumoto, S., Nakano, T., \& Sugiyama, M. (2019). Degradation and fault diagnosis of photovoltaic cells using impedance spectroscopy. Solar Energy Materials and Solar Cells, 194, 130 - 136. doi: https://doi.org/10.1016/j.solmat.2019.01.040

Laronde, R., Charki, A., \& Bigaud, D. (2013). Lifetime estimation of a photovoltaic module subjected to corrosion due to damp heat testing. Journal of Solar Energy Engineering, 135(2), 021010. doi: http://dx.doi.org/10.1115/1.4023101

Mittal, M., Bora, B., Saxena, S., \& Gaur, A. M. (2018). Performance prediction of pv module using electrical equivalent model and artificial neural network. Solar Energy, 176, 104 - 117. doi: https://doi.org/10.1016/j.solener.2018.10.018

Ndiaye, A., Charki, A., Kobi, A., Kb, C. M., Ndiaye, P. A., \& Sambou, V. (2013). Degradations of silicon photovoltaic modules: A literature review. Solar Energy, 96, 140 - 151. doi: https://doi.org/10.1016/j.solener.2013.07.005

Ndiaye, A., Kb, C. M., Ndiaye, P. A., Charki, A., Kobi, A., \& Sambou, V. (2013). A novel method for investigating photovoltaic module degradation. Energy Procedia, 36, 1222 - 1231. doi: https://doi.org/10.1016/j.egypro.2013.07.138

Olayiwola, O. I., \& Barendse, P. S. (2018). Characterization of silicon-based photovoltaic cells using broadband impedance spectroscopy. IEEE Transactions on Industry Applications, 54(6), 6309-6319. doi: 10.1109/TIA.2018.2850025

Omazic, A., Oreski, G., Halwachs, M., Eder, G., Hirschl, C., Neumaier, L., ... Erceg, M. (2019). Relation between degradation of polymeric components in crystalline silicon pv module and climatic conditions: A literature review. Solar Energy Materials and Solar Cells, 192, 123 - 133. doi: https://doi.org/10.1016/j.solmat.2018.12.027

Osawa, S., Nakano, T., Matsumoto, S., Katayama, N., Saka, Y., \& Sato, H. (2016). Fault diagnosis of photovoltaic modules using ac impedance spectroscopy. In IEEE international conference on renewable energy research and applications (icrera) (p. 210-215). doi: 10.1109/ICRERA.2016.7884539

Osterwald, C., Anderberg, A., Rummel, S., \& Ottoson, L. (2002). Degradation analysis of weathered crystallinesilicon pv modules. In Conference record of the twentyninth IEEE photovoltaic specialists conference, 2002. (pp. 1392-1395). doi: 10.1109/PVSC.2002.1190869

Silva, A. M., Melo, F. C., Reis, J. H., \& Freitas, L. C. (2019). The study and application of evaluation methods for photovoltaic modules under real operational conditions, in a region of the brazilian south- east. Renewable Energy, 138, 1189 - 1204. doi: https://doi.org/10.1016/j.renene.2019.01.129

Váry, M., Sály, V., Packa, J., Perný, M., \& Schlosser, V. (2015). Diagnostics and testing of photovoltaic devices. In 38th international spring seminar on electronics technology (p. 208-212). doi: 10.1109/ISSE.2015.7247991

\section{BIOGRAPHIES}

Dr. Aramis Perez received his B.Sc. degree and Licentiate degree in Electrical Engineering from the University of Costa Rica. He received his master degree in Business Administration with a General Management Major from the same university. He also received the Doctorate in Electrical Engineering degree from the University of Chile. Currently he is a Research Fellow at the Fault Diagnosis and Failure Prognosis Laboratory and the Energy Center of the University of Chile. Also, he is a Professor at the School of Electrical Engineering at the University of Costa Rica. His research interests include parametric/non-parametric modeling, system identification, data analysis, and manufacturing processes.

Dr. Luis G. Marin received the Electronic Engineering degree from the University Autonoma de Colombia, Bogota, in 2003, and the M.Sc. degree in information sciences and communications from the University Distrital Francisco Jose de Caldas, Bogota, in 2012. He also received the Ph.D. degree in Electrical Engineering from the University of Chile, Santiago. He is a researcher at Cycle System SAS. His current research areas include control systems for operation and coordination of microgrids, and development of prediction methodologies with the uncertainty characterization for electricity demand and renewable energy resources.

Fernando Fuentes received her B.Sc degree in Electrical Engineering at the University of Santiago of Chile in 2016. Fernando is an Engineer at Centro de Energa (CE-FCFM). His main research interest is microgrids design and control.

Dr. Patricio Mendoza-Araya received the B.Sc. degree in electrical engineering from the University of Chile in 2007, and the Ph.D. degree from the University of WisconsinMadison in 2014. He is currently an assistant professor at the Electrical Engineering Department of the University of Chile. Patricio is a researcher at Centro de Energa (CE-FCFM) and SERC Chile. His research fields include several aspects of microgrids control, stability, protection and power quality, as well as electric vehicles and renewable energies.

Dr. Guillermo A. Jimenez-Estevez was born in Bogota, Colombia. He received the B.Sc. degree in electrical engineering from the Escuela Colombiana de Ingeniera, Bogota, in 1998 and the M.Sc and Ph.D. degree. from the Universidad de Chile, Santiago, in 2003 and 2010 respectively. He was Director of the Energy Center of Physical and Mathematical Sciences Faculty of the Universidad de Chile and currently is visiting professor at Universidad de los Andes, Colombia. His main research interests are power systems planning and operation, renewable energy, distributed generation, smart grids, microgrids and regulation.

Dr. Marcos E. Orchard received the B.S. degree and a Civil Industrial Engineering degree with electrical major from Catholic University of Chile. He also received the M.S. and Ph.D. degrees from The Georgia Institute of Technology, At- 
lanta, GA, USA. He is currently an Associate Professor with the Department of Electrical Engineering, and the head of the Fault Diagnosis and Failure Prognosis Laboratory at the University of Chile. His current research interest is the design, implementation and testing of real-time frameworks for fault diagnosis and failure prognosis, with applications to battery management systems, mining industry, and finance. 